\title{
Sharedness and privateness in human early social life
}

\author{
Action editors: Luca Tummolini and Cristiano Castelfranchi \\ Maurizio Tirassa *, Francesca Marina Bosco, Livia Colle \\ Università di Torino, Dipartimento di Psicologia e Centro di Scienza Cognitiva, via Po, 14, 10123 Torino, Italy
}

Received 6 April 2005; accepted 7 November 2005

Available online 3 March 2006

\begin{abstract}
This research is concerned with the innate predispositions underlying human intentional communication. Human communication is currently defined as a circular and overt attempt to modify a partner's mental states. This requires each party involved to possess the ability to represent and understand the other's mental states, a capability which is commonly referred to as mindreading, or theory of mind (ToM). The relevant experimental literature agrees that no such capability is to be found in the human species at least during the first year of life, and possibly later. This paper aims at advancing a solution to this theoretical problem. We propose to consider sharedness as the basis for intentional communication in the infant and to view it as a primitive, innate component of her cognitive architecture. Communication can then build upon the mental grounds that the infant takes as shared with her caregivers. We view this capability as a theory of mind in a weak sense.
\end{abstract}

(c) 2006 Elsevier B.V. All rights reserved.

Keywords: Communication; Mindreading; Theory of mind; Consciousness; Subjectivity; Sharedness; Privateness; Social cognition; Nativism

\section{Introduction}

The topic of the architecture of the human mind lies at the intersection of several debates within the cognitive sciences. Our work is grounded in three perspectives, namely, contemporary theories of human situated action and communication, the literature concerning mindreading (that is, the capability of representing another individual's mental states, also known as theory of mind), and current advancements in developmental cognitive science. We consider human cognition to be a biological, innately structured property of our species, whose remote roots are to be found in our evolutionary history, and which develops in each individual via the interactions that she ${ }^{1}$ has with herself and with the surrounding physical, cognitive, social, and cultural environment.

More specifically, this research is concerned with the innate predispositions underlying intentional communication.

\footnotetext{
${ }^{*}$ Corresponding author. Tel.: +39 011670 3037; fax: +39 0118159039. E-mail address: tirassa@psych.unito.it (M. Tirassa).

${ }^{1}$ Individual agents will be referred to with the feminine; in the case of communication, the feminine will be used for the first agent only, and the masculine for the partner(s).
}

Contemporary theories define human communication as a circular and overt attempt to modify a partner's mental states. This requires each party involved to possess the ability to represent and understand the other's mental states, a capability which is commonly referred to as mindreading, or theory of mind (ToM). The relevant experimental literature agrees that such capability appears in the human species toward the end of the first year of life or later, depending on precisely how this faculty is defined and investigated. A problem then arises concerning communication in early infancy, since it cannot rely on mindreading proper as is commonly thought of adult communication.

This paper aims at advancing a solution to this problem. We will consider the capability to share as the basis for communication in the newborn and view it as a primitive, innate component of her cognitive architecture. Communication can then build upon the mental grounds that the newborn shares with her caregivers.

We view this capability as a theory of mind in a weak sense. Full-fledged ToM requires the awareness that the partner is an agent endowed with private and autonomous mental states of his own, which may resemble but are not necessarily 
identical to those that we ourselves have. This allows to reason upon, verbalize, or anyway describe such states of the partner's. We will argue that this capability develops later, as the infant acquires the ability to discriminate between what is actually shared with a specific partner (or set thereof) and what is not, that is, as she realizes that mental states are private of each agent's own, that only some of them may be considered shared with the others, and that something needs usually be made in order to make a mental state shared with other individuals. Before she reaches this knowledge, she will not care about what the partner's mental states are and, concerning her own ones, she will take them as simply and inherently shared with the caregiver.

Our position does not contravene the available empirical evidence concerning ToM, in that we do not argue that explicit ToM is already manifest in the young child, but that she can communicate by resorting to a more primitive - and yet fully human - ability of plain sharedness.

\section{Human communication}

The roots of contemporary studies of human communication trace back to mentalist readings of work done in the philosophy of language by Austin (1962), Grice (1989) and Searle $(1969,1979)$, as well as to later attempts to formalize their theories in a computational perspective (e.g., Allen \& Perrault, 1980; Cohen \& Perrault, 1979; Cohen, Morgan, \& Pollack, 1990). The overall framework so developed was then adopted by researchers more interested in understanding the actual functioning and activities of the human mind (e.g., Airenti, Bara, \& Colombetti, 1993; Clark, 1992, 1996; Sperber \& Wilson, 1986; Tirassa, 1997, 1999a).

The idea behind this area is that the actual meaning of any communicative action is not univocally predefined as an a priori by the actor, but results from a cooperative process in which all the agents involved take an active part (Bara \& Tirassa, 1999). Communicative interactions, in other words, take place against a background which is common to the interlocutors. This common background includes an amount of knowledge about each agent's private and public mental states, reciprocal expectations, and other types of social and cultural knowledge: it provides a framework within which each agent can plan her communicative actions and understand those produced by the partner. This background is continuingly contracted and revised during dialogue: its creation and flexible modification thus requires both interactants to actively play their role and coordinate with each other.

Communicative meaning is dealt with in terms of ascription. The meaning of a communicative action is the meaning that each agent involved gives to something that one of them has intentionally and overtly done (or not done). Communicative actions, in this framework, have no meaning per se: their meaning is to be found in the mental states that the participants entertain.

These approaches to communication require the agents involved to recognize each other as another agent in his turn, that is, as an individual endowed with mental states that are representations of the world, of the agent himself, of the ongoing interaction, and so on. This is commonly known as the requirement that the agents entertain a theory of mind.

This framework, which we substantially accept, creates a problem as far as infant communication is regarded (see also Airenti, 1998; Bosco \& Tirassa, 1998; Risjord, 1996), because the evidence available is that this capability appears comparatively late in infancy. It therefore seems to follow that children, at least during their first year of life, are incapable of Gricean communication.

In principle, this problem might be solved by adopting two different theories of communication: a mentalist one, based on the reciprocal modification of the interactants' mental states and capable of explaining adult communication, and a nonmentalist one, based on a different process and solely dedicated to the explanation of infant communication. This, however, would create more problem than it would solve. We argue that it is more reasonable to adopt the same mentalist approach both to adult and to infant communication, provided that the Gricean framework be revisited in certain crucial places, so to make it fit for the description of children's communication.

We will start from a conception of mindreading as a biological capability of the human mind, which undergoes development during ontogeny. Nativism and ontogeny are not incompatible in modern biology: indeed, they are two sides of the same coin (see for example Lewontin, 2000).

Thus, to say that mindreading is innate does not imply that it remains unchanged from birth up to the adult age, or that infants can read a partner's mind or understand how, when and why - or even that - a partner's mental states may be different from those of their own. Our view is instead that the ontogeny of mindreading begins with the innate capability to share mental events with the partners in interaction, and that this ability is present at birth, or immediately after birth. A suitable notion of sharedness will be provided in a later section.

The ability to entertain proper theories of the mind appears later in infancy and builds on the maturation of the ability to differentiate between those mental events which are shared and those which are private, as well as on other linguistic and cultural acquisitions.

Our approach is compatible with the existing empirical literature, which we, however, integrate in a novel theoretical interpretation; furthermore, such theoretical interpretation allows for an account of early social life which is compatible both with the fact that young children do interact with their caregivers in a fully human way and with the fact that their ways are nonetheless different from those that adults have.

\section{Current studies of the nature and the acquisition of mindreading}

Mindreading, or Theory of Mind (ToM), is an agent's capability of representing another individual's mental 
states, so to be able to understand, predict and explain his behavior. This capability is a key pillar of human social life; to be able to understand events in a mentalist framework is a huge evolutionary change, which allows for an array of features and activities ranging from mentalist communication to culture, history, and pedagogy.

In this section we will briefly overview the main studies and explanations of the nature and the ontogeny of mindreading that are available in the literature.

(i) Simulation accounts. According to simulation theories (e.g., Goldman, 1993; Gordon, 1986, 1996; Harris, 1991), it is by using the introspective awareness that we have of our own mental states that we are able to infer those of the others. In order to understand another individual's actions, we would imagine to be placed in her situation and doing what she is doing, and would observe what is going on inside ourselves. Then, we would attribute to the other agent the thoughts and feelings that we would have if we were her.

Simulation accounts offer the advantage of not being (or not necessarily being) committed to the arrows-and-boxes perspective which is implicit or explicit in classical cognitive science. They remain, however, somewhat obscure concerning the architecture and functioning of the decoupling/ simulation processes that they posit, as well as, most importantly for our current purposes, its ontogeny.

Simulation accounts - or, more precisely, motor accounts of mindreading, which are a subset of simulation approaches - have lately gained increasing appeal after the discovery of mirror neurons (Rizzolatti, Fadiga, Gallese, \& Fogassi, 1996), which has sometimes been interpreted as evidence in their favor (Gallese \& Goldman, 1998; Gallese, Keysers, \& Rizzolatti, 2004). This view, however, is not exempt from criticism (e.g., Jacob \& Jeannerod, 2005).

(ii) Theory-theory accounts. Another body of literature, commonly known as theory-theory, claims that a mindreader would employ mental states as theoretical constructs in the prediction and the explanation of behavior. On this view, which gets the closest to accepting Dennett's $(1978,1987)$ proposals, our knowledge of the mind makes up an everyday framework theory (Carey, 1995; Gopnik, 1993).

In this perspective, learning and experience play a key role in the acquisition of mindreading: the child, like a scientist, would conjure up several successive theories of mind, always discarding the current one whenever it is falsified by new data collected. The final result of this process would be the adult's representational theory of mind.

A problem with theory-theory accounts is that they require too much intelligence and cognitive effort on the part of the child. Furthermore, since the details of each child's experiences will presumably be different from those of the others, they do not explain why all the children would devise the same theories at approximately the same ages, unless this learning, theory-building and theoryfalsifying activity is constrained by specific knowledge or processes. Even more basically, it is not clear why a child would devise the very notion of mental events at all, in the absence of innate features like a primitive, irreducible capability of introspection and mindreading.

The very existence of the mind, as well as our ability to recognize its presence and functioning in ourselves and in other agents and to understand its relatedness to the world, cannot be cultural or individual constructions. While specific features of an adult's culture necessarily play a role in her theory of mind, our primitive notion of mind and the basic ontology on which our everyday mindreading builds have to be primitive and innate in our cognitive architecture.

(iii) Modularity accounts and the "precursors" of mindreading. A third group of theories (e.g., Baron-Cohen, 1995; Leslie, 1994a) maintains that mindreading is not something that a child may learn, but an innate mechanism that undergoes spontaneous development in a favorable environment. The end point of this process would be the child's capability of representing cognitive agents as holding true and false propositions about the world, such as pretending that $\mathrm{p}$, believing that $\mathrm{q}$, desiring that $\mathrm{r}$, and so on.

Because the idea of innate is most commonly associated in the cognitive sciences with the idea of module, and because several accounts of autism and schizophrenia point at specific impairments of mindreading (Baron-Cohen, Leslie, \& Frith, 1985; Frith, 1992), these theories typically conceive of mindreading as yielded by the functioning of a module.

Criticisms may be addressed to modularity theories at different levels. First, the very notion of a mental module ${ }^{2}$ is only useful - and understandable - within the realm of computational psychology, a paradigm which we, like many other researchers, see no reason to accept (Bateson, 1972; Bruner, 1990; Edelman, 1992; Johnson, 1987; Nagel, 1986; Searle, 1980, 1992; Tirassa, 1999b; Varela, 1996; Varela, Thompson, \& Rosch, 1991). Mental competences regarding plans, actions, and the social and communicative life of human beings, in particular, are more easily understood as sequences of mental states (Tirassa, 1999a, in press) than in terms of the processing of internally coded and stored symbols.

A second type of problems with modularity theories concerns their view of the ontogeny of mindreading: specifically, the notion of precursor. Precursors are social skills or behaviors which appear earlier than full-fledged theory of mind and allegedly entertain relations with it that are both important and developmental. The role that these antecedents may play in a theory of the development of mindreading is two-folded. First, they are supposed to explain and justify the pre-ToM child's social and communicative inter-

\footnotetext{
${ }^{2}$ There actually are at least two notions of module, advanced, respectively, by Fodor $(1983,2000)$ and by the supporters of distributed architectures in evolutionary psychology (e.g., Barkow, Cosmides, \& Tooby, 1992; Cosmides \& Tooby, 1994a, 1994b) and elsewhere (e.g., Minsky, 1985). Our arguments apply to both.
} 
actions; second, they are supposed to pave the way for the later appearance of mindreading proper.

Baron-Cohen (1995), for example, has claimed that a fully functioning ToMM (Theory of Mind Mechanism: Leslie, 1994b) would be identifiable around the fourth year of age, as the final step of a developmental sequence which would include the successive activation of several precursors: first, an innate intentional detector, followed by an eye direction detector and a shared attention mechanism. Other precursors of mindreading have been identified in joint attention (Garfield, Peterson, \& Perry, 2001; Tomasello, 1995), imitation and emotion sharing (Meltzoff \& Gopnik, 1993), the infant's emotional reaction to others (Hobson, 1993), and so on.

Such notions of precursor, however, are often ill-defined. To claim that a certain skill or mechanism is a precursor of mindreading is to claim that the former plays a causal role in the ontogeny of the latter; that is, that the relation between them is more than just chronological. For example, one might want to claim that an early cognitive function causes or guides, or contributes in causing or guiding, the later appearance of another; or that the latter is a more developed version of the former and therefore somehow subsumes it; and so on. However, precisely this type of reasoning is generally left implicit or unclear, with the consequence that most of these accounts are mere chronological sequences; yet, just because one cognitive function appears at an earlier age than another does not mean that the former is a precursor of the latter.

The ontogeny of an organ or function (whether mental or otherwise) should be understood and described in terms of a developmental dynamics leading from an initial state to a mature (adult?) state. However, the alleged precursors of mindreading can serve neither as the initial state of such competence nor as steps in its development, because of other difficulties in which the notion of precursors incurs.

Imitation, joint attention, etc., are activities in which a child will only engage every now and then. To view them as the precursors of mindreading leaves us in ignorance about how and why a child should engage in them, and what her social life is supposed to be in all the moments when she is not acting them out.

Furthermore, to view those (or other) activities as precursors of mindreading is to conceive of performance, that is, a type of behavior, as the precursor of a competence or mental function, like mindreading. Joint attention, to name one, is something that a child does, not something that she thinks. Thus, accounts in terms of precursors are obscure as to what internal thoughts, representations or processes are supposed to underlie the child's engagement in these activities.

In general terms, to explain the existence of joint attention by appealing to a "specialized inner mechanism whose functioning enables the child to act out joint attention" is unlikely to shed any light on the architecture and functioning of the child's mind. In general, to just posit a suitable piece of internal machinery for each type of behavior observed (that is, to posit that an infant is capable of imitating because she is endowed with an imitation device or module, and so on) offers no explanation. Just because such line of reasoning is so widely diffused in cognitive psychology does not make it more informative.

Finally, an agent's engagement in an activity is sensibly understood only against the background of a certain worldview on her part (Carassa, Morganti, \& Tirassa, 2004; Carassa, Morganti, \& Tirassa, 2005; Clancey, 1997a). In order to try and share attention with a certain entity of the world, an agent would first have to represent that entity as apt-to-share-attention-with. You just do not try to share your attention with an entity which you do not think will appreciate your attempt. This means that a suitable subjective ontology has to be ascribed to the child, able to provide for such background and thus to make sense of the child's representations and actions.

To sum up: to understand what activities an infant can engage in, and why, is only possible in the framework of a theory of what is inside her mind that makes it possible, interesting and worthwhile for her to engage in such activities.

\section{Mindreading and communication in early infancy}

There exists a great deal of evidence to the effect that, starting from the very first weeks of life, human beings respond to their conspecifics' actions, are sensitive to the quality of communication, are capable of regulatory behavior in face-to-face interaction, and react appropriately to disruptions that may occur in interaction.

Young infants are highly sensitive to the contingent relations between their actions and certain events that take place in the surrounding environment (Papousek \& Papousek, 1974; Rochat \& Morgan, 1995).

On this basis, some have argued that the nature of social interactions develops from nonmentalistic to mentalistic (Gergely \& Watson, 1996; Thompson, 1998). Children would begin treating others as entities with whom to share behaviors, and grow up to treat them as persons with whom to share knowledge, goals and intentions. These researchers have argued that early affective and social interactions can be explained without positing a mentalistic worldview on the part of the child: her social life would consist of interactive behavioral exchanges whose contingency structure would suffice for an explanation of her behavior, with no possibility or need for mentalistic representations. Gergely and Watson $(1996,1999)$ have thus claimed that infants are initially incapable of viewing others as intentional agents or of reading their minds, and that they simply deploy a contingency-detection mechanism built in their perceptual system. They have also suggested that the infants' innate social reactivity, as it surfaces for example in their early contingent affectregulative interactions, serves to establish a precondition for intersubjectivity; the latter will only appear during later development. 
It is a major feature of this position that infants would pass the first part of their life without reading minds; as we have discussed above, this would also imply that they are incapable of communicating with the caregivers.

This picture does not seem to us to provide a viable strategy for understanding early infancy. Indeed, other bodies of literature paint a sharply different picture of the young infant's mind. Current biosocial views maintain that mother and infant form an affective communication system since the very beginning (Bowlby, 1969; Stern, 1985; Trevarthen, 1979). Infants have an early ability to interact with other human beings (which presupposes, of course, that they are sensitive to their presence and capable of recognizing them and orienting toward them: Meltzoff \& Moore, 1983, 1989; Morton \& Johnson, 1991; Stern, 1985). Meltzoff and Moore $(1983,1997)$ have suggested that infants understand that others persons are autonomous agents because they recognize them as "like me" ever since birth. Meltzoff and Gopnik (1993) have argued that imitation and mindreading itself are increasingly complex manifestations of the ability to form and co-ordinate representations of oneself and of the others.

Researchers subscribing to an intersubjectivist position have claimed that infants are born with an innate capability of identifying and ascribing mental states like intentions and feelings, which they would be introspectively aware of (Braten, 1992; Stern, 1995; Trevarthen, 1993a). Infants would recognize their own mental states as similar to the corresponding ones of the other humans and would experience such states as shared with them. Stern, for example, has suggested that "from a very early age, the infant perceives intentions in the self and the other" and that she "sees past" overt behaviors in order to read in them the intentions that organize them (Stern, 1995, p. 420).

Trevarthen (1993b) has suggested that infants are born with a dialogic mind and the innate sense of a "virtual other". He has viewed the affectively rich interactive exchanges between mother and infant as testimony to the existence of "primary intersubjectivity". Primary intersubjectivity would be measurable as the level of contingency between the behavior of the mother and that of the infant.

In the same vein, there are several studies of the active role that very young children play in their communicative interactions with adults. For example, Reddy, Hay, Murray, and Trevarthen (1997) have claimed that, beginning in the first two months of life, infants show a mutual communicative behavior with the caregiver and that they are capable of regulating their actions in accordance with his actions and feelings. Fogel (1993) has argued that early communication builds on a continuing process of modification of each party's current behavior as a response to the other's acts, and that both the infant and the adult contribute to such process. When interacting with an adult, 2months-old children show regularities in the timing of behavioral (Trevarthen, 1993a) and turn-taking (Trevarthen, 1993b) interactions. They also appear to be conscious that they are engaged in a mutual interaction: when a disruption occurs in the partner's communicative behavior, they protest by vocalizing and moving their arms while aiming their gaze to his face (Cohn \& Tronik, 1989; Murray \& Trevarthen, 1985).

At around 9-12 months, the infants' self-awareness apparently undergoes a change as they become more aware of their effectiveness as agents and more active in their participation to communicative interactions (Bruner, 1977; Reddy et al., 1997). Several social and communicative abilities appear at this age, like pointing at and reaching to objects, following a partner's gaze, looking for eye contact in interaction, and using other people's emotional expression as a reference to guide their own behavior. Pointing is also used as a proto-declarative act (Bates, Camaioni, \& Volterra, 1979).

Many such behaviors involve joint attention. This is the coordination of two or more persons around a common focus of interest; coordination here means that each of the agents involved is not only attending to the same object or event, but, crucially, that she is also aware that the other(s) are doing the same, and acts accordingly.

Joint-attention skills appear progressively at around 915 months of age (Carpenter, Nagell, \& Tomasello, 1998) in a predictable order. The earliest joint-attention activities consist in the infant checking that the adult is attending to a certain object or event; the next consist in the infants following (monitoring) the adult's attention to an object or event; and, finally, the latest appearing joint-attention activities consist in the infant actively directing the adult's attention to the object or event of her interest (e.g., by way of pointing or vocalizing). Joint attentional activities are linked to the emergence of linguistic skills; indeed, language itself may be viewed as one of the forms they take.

Therefore, it is around the first birthday that infants begin to exhibit a genuine understanding of other persons as intentional and attentional agents: for example, they become capable of recognizing that an adult who is interacting with them tends to pay attention to and to get excited about a new toy and of identifying what toy is new for him even though it was not new for them (Tomasello \& Haberl, 2003).

\section{Dynamics of the embodied mind}

\subsection{Mental states and their contents}

Most contemporary theories of agency and communication, whether they take a philosophical, psychological, or computational perspective, are cast in mental states terms; that is, their framework is what Rao and Georgeff (1992) have called BDI architectures - the acronym stands for belief, desire, and intention. In this framework, an agent's mind is described in terms of the types of mental states and their contents and/or of the sequences of such states that it may entertain. 
Since, however, there is little consensus in cognitive science as to the precise meaning of mental states terms, a clarification of our own position is required.

We define an agent as a conscious organism who lives in a dynamic situation (that is, in a subjective, open, and revisable interpretation of the environment), striving to make it more to her liking (Tirassa, 1997, in press). An agent's mind consists in a flow of consciousness, that is, in a flow of subjective, meaningful representations of the environment.

More precisely, in the case of the human species, the mind consists in a flow of subjective, meaningful representations of the very agent's interactions with its subjective environment as it is, was, or could be. In other words, in agreement with other researchers (e.g., Searle, 1992; Varela, 1996; Varela et al., 1991) we conceive of terms like mind, consciousness, representation, semantics, and Intentionality as substantially synonymous.

For the purpose of description, this conscious flow may be conceived of as a dynamics of mental states like perceptions, emotions, beliefs, dispositions, intentions, etc. Mental states can in turn be described as characterized by a mode (e.g., desire, intend, fear, belief, and so on) and a semantic content (the entity that is being represented). Examples of mental states are Ann believes that it is raining, Ann fears that it will rain, or Ann intends to take an umbrella. ${ }^{3}$

Thus, for an agent to entertain a certain mental state is for her to be in a certain semantic relation with the world; the various types of mental states that she may entertain are therefore defined according to the different types of semantic relations that she may have with the world (Searle, 1983). Theories may be formulated where, for example, terms like "belief" are used to refer to the agent's knowledge of the situation at a given time, terms like "desire" are used to refer to her potential goals, terms like "intention" are used to refer to her actual goals, and so on.

Human cognition may thus be said to include the classical epistemic and volitional states like beliefs and intentions, as well as other types of awareness like different types of emotions, hunger, fear, and so on.

All Intentional states are representational inasmuch as they are endowed with contents; they are, in a sense, all equal in nature. However, they may obviously vary in complexity and abstraction: my belief that $E=m c^{2}$ is, in this sense, not equal to my belief that it is raining outside, despite their "direction of fit" (Searle, 1983) is the same.

\footnotetext{
${ }^{3}$ It may be useful to remark that we are not saying that mental states literally exist as such in an agent's mind/brain; that is, our use of this terminology is not meant to commit us to the views (a) that the functioning of the embodied mind is characterized by still states with instantaneous transitions from one to another, like photograms in a motion picture, (b) that each "photogram" in this continuous flow is a token of some abstract type or family of such still states, and (c) that the embodied mind at each instant entertains only one of such "photograms". In this respect, our view is more resemblant of that of Varela et al. (1991) than that of Searle (1992). See also Tirassa (1999b, in press).
}

Analogously, my fear that the national economy may decline over the next semester bears little relation to my fear that that pack of wolves over there will attack me if they smell me. Thus, further differences should be introduced within each type of Intentional state. While this is commonly acknowledged as far as intentions are concerned (e.g., Bratman, 1987, 1990; Searle, 1992), less attention has been paid to other types of states, like the epistemic or the emotional ones (e.g., Premack, 1988).

Actions are the external counterpart of these mental dynamics: for example, when I meet a friend, I can rejoice, smile, and shake hands with him. This happens because I represent the whole situation in which I find myself as characterized by certain salient features (that there is a friend over there is more interesting than, say, that there is a man drinking a coffee in the bar on the left), which may generate certain emotions (meeting a friend may cause me to be happy), to which I react by generating certain desires and intentions. This leads me to engage in a socially shared activity - what happens is that I walk toward my friend smiling and offering him to shake hands.

The entities that an agent's mind is sensitive to and able to represent - in Intentional terms, the possible contents of her mental states - make up her subjective ontology (Tirassa, Carassa, \& Geminiani, 2000). This may comprise different types of objects, relations, events, and actions. The subjective ontology of a highly sophisticated social species like ours includes social objects (individual agents, groups, etc.) along with their features (beliefs, intentions, etc.) and with the events, actions, activities, and relations that they may participate in.

\subsection{Mind dynamics}

We have said that the mind consists in a flow of subjective, meaningful representations that may be described as mental states; for example, when I see a friend, I rejoice, I smile, and I offer to shake hands with him.

Whence do these dynamics come? That is, how comes that seeing a friend makes me feel glad, smile, and move my body in a certain manner?

This question must be divided into two other ones. The first concerns the mere fact that mental states follow each other with some relation of causality; that is, how comes that seeing someone may generate other mental states at all? Unless one is willing to be a dualist, and therefore to accept the problems that then follow, consciousness and Intentionality have to be conceived as material properties of an agent's functioning body - hence talking of mind always implies talking of mind/body, rather than of mind (or of body) alone. Like all the material properties of a physical object, the state of an agent's mind/body at any slice of time will play a causal role in the state of her mind/body at the following slice of time (Tirassa, 1999a), together with co-occurring relevant factors that may affect its functioning, like the activity of sensory receptors or of various types of chemicals like oxygen, glucose or drugs. 
An agent's cognitive dynamics across time thus results from the interaction of her mind/body with the internal and the external (physical, cultural, and social) environment.

The second question concerns the specific pattern with which mental states follow each other; that is, how comes that seeing a friend generates those emotions, intentions, and actions, rather than any other possible one? These specific patterns are rooted in the phylogenetic and ontogenetic history of the agent, as well as in her current interests and feelings. What can be said in general terms is that they depend on the worldviews that the agent maintains. Worldviews are frameworks of interpretation that provide for the meaning that a certain situation and its current features have for a certain agent at a certain time.

For example, my intention to stand up from this chair, go to the fridge and take a beer only makes sense because it is part of my current worldview that I am sitting, that I might use a beer, that there is one in the refrigerator, that the floor that lies between me and the refrigerator will sustain me while I walk, that I will be able to open the refrigerator and recognize the beer can when I see it, and so on.

As we have said above, an agent's engagement in an activity is sensibly understood only against the background of a certain worldview on her part (Carassa et al., 2004, 2005; Clancey, 1997a). Worldviews need not be fully represented for an agent to engage in an activity. We usually do not take into account the possibility that the floor of our kitchen is not as solid as it seems; nonetheless, it is because we take it for granted that it is that we can engage in the beer-taking activity.

Being educated adults, we can, of course, focus on some features of the worldviews we are currently engaged in, and possibly reason upon them or verbalize them: but this is a mental and social activity in itself, in which language and education (and, in general, ontogeny) play a key role, and is not necessarily part of the beer-taking activity. Indeed, most of the times we drink beer without feeling any need to verbalize the worldviews that underlie such activity - and, even when we decide to do so, we can only verbalize a small subset of the features of our worldviews. $^{4}$

\section{Social and communicative agency in early infancy}

\subsection{The infant as agent}

Human beings are agents ever since birth: an infant is, in her own way, as active an agent as an elder child or an adult. Her goals may sometimes be unclear to the caregiv-

\footnotetext{
${ }^{4}$ Our notion of worldviews may resemble Searle's (1983) notion of Background. While we have no space to discuss the similarities and differences, we have opted for a different label because we think that there are certain difficulties inherent to Searle's Background which we do not want to inherit here. Our notion of worldviews is meant to stand on an autonomous ground.
}

ers or the researcher; sometimes she may have no precise goal at all; but this does not detract from the existence of a rich web of meaningful interactions with the physical and social world that surrounds her.

If infants are to be treated as agents, then Intentional or BDI language is as fitting for the description of their minds as it is for the description of adult minds. This does not mean that an infant will necessarily entertain the same mental states that an adult will. To apply here the reasoning we have discussed above: an adult's epistemic state that $E=m c^{2}$, with its required competences related to language, "metacognition", abstract reasoning capabilities, culture and education, etc., has to be both similar to and different from a neonate's epistemic state that mommy is in front of her.

There are at least two reasons why these two states are similar. The first is that both are epistemic in nature: they characterize an agent's knowledge of the world. They provide, in other words, the only possible basis on which an intelligent agent may act in the world. The second reason why they are similar is awareness: the adult is aware of the complex relations between energy and matter that are described by modern physics, and the neonate is aware that mommy stands there in front of her. What makes the two states different is their origin and consequence: the adult knows that $E=m c^{2}$ because of a long history of education and reasoning, which allows for the possible generation of further reasoning on the subject (in the line of what we have said above regarding worldviews and activities); the neonate knows that mommy stands there in front of her because she sees mommy, which allows for the possible generation of emotions (e.g., joy), desires (e.g., the desire of playing with mommy) and activities (e.g., engaging in a playful interaction with mommy).

(Of course, most of the states that occur in an adult's mind are much less abstract and rational in nature: adults happen to just drink a beer in front of the television, to just smile when they meet a friend, and so on, more often than they happen to engage in relativistic reasoning.)

For example, a child's fear of thunders can be described as a mental state whose mode is fear and whose contents is a representation of thunders. Of course, a prelinguistic baby will have no words to refer to those frightening sounds she hears, nor will she have a theory of what thunders are and where they come from. On the other hand, there is no reason to think that language or scientific-like theories are required for mental representations to exist. Language and education add layers of complexity, "metacognitive" skills and strategies, and so on, but they do not create the representational mind: they only modify its ontogenetic trajectory (Clancey, 1997b; Cole, 1996; Guidano, 1987, 1991).

Mental states are biological phenomena: they are the property of a functioning body. From a psychological viewpoint, to be a human being means to be able to entertain the mental states typical of our species; more precisely, to be a human infant means to be able to entertain the 
mental states that are typical of human infants, and so on. A developing individual will progressively become capable of entertaining more sophisticated mental states, which will bring in turn to progressively more complex physical, social and communicative interactions with the surrounding environment, with the other agents, and with oneself.

Thus, although a neonate's interactions are somewhat simpler than those of an adult, they are nonetheless the interactions typical of an agent endowed with epistemic, volitional, and intentional states that we will call early forms of beliefs, intentions, emotions, and so on. The problem is to capture this simplicity without losing sight of the species-typicality.

\subsection{Sharedness}

An Intentional description of human infants leads to ask what mental states they may entertain and what role such states play in their communication with the caregivers, thus looking for a solution to the problem posed by the lack of mindreading in the first part of life.

Let us remind the outline of the problem. Human communication is essentially a mental phenomenon, involving the mental states of the participants and, crucially, the mental states that each participant is capable of ascribing to the partners. A problem arises because the relevant experimental literature shows that human infants have no such capability at least during their first year of life. It would therefore follow that children are completely incapable of communication, at least during their first year of life, or that they must resort to a completely different way of communicating - two hypotheses that we find unacceptable.

Our proposal is instead that an infant may communicate by resorting not to full-fledged mindreading capabilities, but simply to the capability of sharing her mental states with her partners, provided that she is incapable of not sharing them.

Sharedness is an agent's ability to construe her own mental states as mutually known to a partner. Our use of this notion requires a brief detour. ${ }^{5}$

Human communication is an overt social interaction between one agent who means something by a certain action and another one who reconstructs the presumed communicative meaning. According to Grice (1957), communication involves the agent's intention that the partner recognize her intention as communicative. This makes the process a somewhat circular one, in that each party knows that the first agent relies on the partners' ability to comprehend her move and each party also knows that all know

\footnotetext{
${ }^{5}$ Please note that other researchers would use the label common knowledge to refer to something similar to what we call sharedness. While we do not have here the space to discuss in detail the differences between the two notions, let us explain that we adopt sharedness both because it is the term commonly used in our scientific area of expertise, namely, theories of human communication, and because we hope to so avoid misunderstandings which might arise from the use of the other label.
}

that she does. This circularity leads to the notion that communication requires that some mental states be shared among the participants.

Let us consider a simple example: Ann says to Bob "Take an umbrella when you go out: the TV said it's going to rain today". According to Grice (1957), this is an instance of communication if Ann, by her utterance, intends (1) to induce Bob to take an umbrella, (2) to let Bob recognize intention (1), and (3) to let such recognition be (at least part of) Bob's reason for taking an umbrella; and if Bob recognizes Ann's intentions (1)-(3).

Strawson (1964) has contended that, in order to rule out certain counterexamples, a further condition is needed, namely that Ann: (4) intends Bob to recognize intention (2). Schiffer (1972) has then remarked that it is also necessary that Ann: (5) intends Bob to recognize intention (3); (6) intends Bob to recognize intention (4); (7) intends Bob to recognize intention (5); and so on ad infinitum. This analysis leads to the conclusion that true communication only occurs when the first agent has, for each $n$th intention of this type, an additional $(n+1)$ th intention that $n$ be recognized by the partner, and when the latter recognizes each of these $(n+1)$ intentions in his turn. The virtual endpoint of this infinite succession of mental states is called mutual knowledge and is supposed to provide the firm ground that the interlocutors need to rely on if they are to communicate safely.

The problem with this argument is that any communicative act would require the actor to entertain an infinite number of intentions, and the partner to recognize and deal with each of them. Furthermore, each agent could safely rely on mutual knowledge only if the partner actually entertained all the relevant mental states, which would in turn require the existence of a suitable confirmation procedure, plus infinite time to implement it. All of these conditions are clearly impossible in the real world. On the other hand, to limit the chain to an arbitrarily finite length (Grice, 1982) or to simply do away with circularity (Sperber \& Wilson, 1986) would not rule out Strawson's and Schiffer's counterexamples.

A way out of this problem has been proposed by Airenti et al. (1993). They have defined common knowledge as a primitive mental state type which they call shared belief: an agent shares the belief that $p$ with a partner if she believes both that $p$ and that the partner shares the belief that $p$ with her.

So defined, shared belief is a mental state among the others. As such, it is subjective (that is, one-sided), primitive (that is, irreducible to private beliefs), and representational (that is, it depends on the viewpoint of the mind who entertains it, and not on the mind of the partner's or on "objective truth"). An agent has neither the necessity nor the possibility to know what is "objectively" shared with a partner. Being ascriptional, sharedness does not require fancy abilities like telepathy or an endless circularity of reciprocal confirmations; nor does it require any more reference to objective facts in the external world than ordinary beliefs 
do. It is thus possible that I take $p$ to be shared with you, whereas you do not believe $p$ or do not take $p$ to be shared with me. The failure of a (supposedly) shared belief may give rise to different kinds of failures, misunderstandings, and deceptions, but creates no more cognitive or epistemological difficulties than the failure of a standard private belief.

The relation between private and shared beliefs in this account is one of inference, not of reduction. For instance, if I believe that you and I have been co-present to a certain conspicuous event $p$, I can legitimately infer that I share with you that $p$. This is my representation, not yours: therefore, it is me, not you, who is committed to the consequences of such shared belief of mine. Analogously, if I believe that you take $q$ to be shared with me, I can legitimately come to believe that you believe that I believe $q$; and, again, I am the only agent committed to the consequences of such belief.

This account captures both the circularity and the overtness of communication in a psychologically plausible way. Sharedness is an agent's ability to construe her own mental states as mutually known to a partner. This is the starting point of communicative interaction, which may then be viewed as the progressive modification of the mental ground that each participant shares with the partner. The whole process is made possible by the fundamental identity of all human beings' cognitive architecture, which allows us to recognize our conspecifics as bearers of mental states that are qualitatively similar to ours, and therefore to view them as plausible communicative partners (Tirassa, 1997, 1999a).

We adopt a similar framework for communication in the first year of life, with some important differences with respect to Airenti et al.'s (1993) account. One is that we take sharedness to be part of the agent's worldviews, and not necessarily of her mental states.

Most of our communicative acts take place on the background provided by sharedness, without our being necessarily aware of it. When we engage in a short chat with a colleague while the elevator brings us to the right storey, for example, we do not focus on sharedness, but on the actual topic of conversation. Sharedness is part of the worldview that we are adopting, and can thus provide the framework of interpretation within which the various communicative acts that we exchange acquire a meaning; but it is not, or not necessarily, part of our conscious states. We can always focus on sharedness and reason upon it or verbalize it - this may happen, for example, when a breakdown occurs in conversation; but that is not a necessary part of our engaging in conversation.

Another difference, with respect to Airenti et al.'s account, is that we take our notion of sharedness to be an innate component of a human being's architecture for social and communicative life, and one which is present at birth, or immediately after birth.

Finally, we inscribe our notion of sharedness in a biological, instead than computational, view of cognition.

\subsection{Infant communication}

The constraints within which a theory of infant communication has to be developed are: (i) that the infant has no ToM in a strong sense, but, nonetheless; (ii) that her way of communicating is fully human. The latter requisite implies that infant communication has to be similar in nature to that of the elder child and the adult, and effective, that is, comprehensible to the latter.

Our proposal is that infants may communicate by resorting not to a full-fledged ToM, but simply to the capability of sharing her mental states with her partners, provided that she is incapable of not sharing them. While the classical approach limits itself to claiming that the infant is unable to ascribe mental states to other individuals, we argue that she must be unable not to take her mental states as shared with the partners. In her earliest stages of life, a child would then take all of her experiential states as shared with her partners.

In our framework, the nature of human cognition is intrinsically social (Vygotsky, 1978, 1981): for an infant to share all of her mental states means that they are, in her worldview, intrinsically public. We do not claim that she has any kind of access to the partner's mental states, nor that she is capable of distinguishing between what she thinks and feels and what another agents thinks and feels, but that she is, subjectively speaking, like a radio, "broadcasting" her mental states for the caregivers to receive them.

If this is the child's worldview, then every action she may perform is performed in the cognitive space that she shares with the partners and therefore has a communicative meaning. In this respect, her intentions are undifferentiated, that is, they are neither strictly private nor strictly communicative, since the difference between the two would require her to be aware that some of her mental states are not actually shared.

Thus, a hungry neonate would simply take it for granted that her caregivers share this mental state of hers, that is, that each of the parties involved knows that she is hungry. ${ }^{6}$ This would bring her to also take it for granted that her hunger will be satisfied. Her cry if this does not happen may then be interpreted as consequent to a failure of this expectation.

In a strictly Gricean account of communication, this cry would not be considered intentionally communicative, since this would require that she be able to draw an explicit distinction between the mental states that she takes as

\footnotetext{
${ }^{6}$ This condition has to be clearly differentiated from another one. To say that the caregiver shares the infant's hunger, in our framework, means that he knows that she is hungry, and that she can take it for granted that he does; but it does not mean that the caregiver should become hungry in his turn, or that the infant thinks that he should. Indeed, it is part of our proposal that the infant has no particular interest in the caregiver's private mental states, if only because she does not realize that private mental states exist at all.
} 
private of her own, those that she takes as private of the caregivers', and those that she takes as shared with them. But, since she is unable to draw such distinctions, she cannot be said to entertain a fully Gricean communicative intention.

If, however, she just takes it for granted that every behavior of hers is public, that is, shared with the caregivers, then private and communicative behavior are simply one and the same thing. In this case, she would indeed communicate with the caregivers, but with no need or possibility to go through the reasoning (ToMrelated and otherwise) that full-fledged Gricean communication requires. Still, her actions would remain firmly on the mentalist grounds that characterize human communication, which would also guarantee that the caregivers be capable of understanding them without having to resort to a supplemental cognitive effort or device, exclusively designed for dealing with children in the first year of life.

Adults only take something as shared with a partner when they have reasons to do so, based for example on co-presence (Clark \& Marshall, 1981; Colombetti, 1993) or on the awareness of a common biological or cultural heritage; but they know that most of their inner states are private of their own and may become shared with a partner only if they decide to act for that goal. That is, sharedness in the adult is the counterpart of privateness.

Furthermore, sharedness in adults may play two role. First, it may be part of the current worldview, that is, of the background within which to participate in communication and to plan and interpret relevant actions. Second, it may be a mental state or part thereof, that is, something which is present to the agent's awareness and which the agent can reason upon and verbalize.

In our proposal, sharedness in the infant is instead a plain state of the world: subjectively, the infant would neither have a privateness of her own nor understand that adults do. All that is needed for this is a primitive, innate recognition of agency, a capability which can safely be ascribed to human beings from the very beginning of their life (Leslie, 1994a; Murray \& Trevarthen, 1985; Premack, 1990; Trevarthen, 1977).

The infant's capability of sharing mental states with the caregiver provides the worldview within which all of the activities in which she engages with him make sense to her. This allows her to generate expectancies about the his behavior (see also Bruner, 1982) and therefore, via the cycle of protointeractions and expectancy violations we have outlined above, to guide it. At the same time, she will focus her attention on the well-defined entities with which she shares her mental states - those entities that are "good to interact with". This helps the caregiver to communicate with the infant and thus begin the explicit and implicit pedagogy which is crucial for the acquisition of language, culture, and the other products of human's highly peculiar biology.

\subsection{Sharedness in the elder child and in the adult}

At around 9-12 months, the child ceases to share all of her mental states with the caregivers, that is, it is no longer part of her worldview that all of her thoughts and feelings are intrinsically public.

This is necessary, because she has now achieved a degree of freedom and autonomy that, while still remarkably limited when compared to that of an elder child or an adult, is nonetheless immensely greater than that she used to have in the previous months. This progress finds a necessary counterpart in the beginning of her ability to discriminate between the mental states entertained by different agents: it would be no more adaptive to take all of her mental states for shared with the caregivers.

This is the beginning of true mindreading. In our view, therefore, the appearance of mindreading does not coincide with the beginning of sociality, but with a restriction of it, namely, with the beginning of privateness.

This is also the beginning of true Intentional communication, conceived of as a specific, local activity in which an agent may or may not engage, as well as, relatedly, of the subjective difference between private actions and truly communicative actions. If sharedness is no longer the standard (indeed, the only conceivable) state of affairs, the child has to do something if she wants to make a mental state of her own actually shared with a partner; conversely, she will also begin to understand that certain thoughts and certain actions may take place on a purely private basis, without the need to share them with anybody and everybody. Publicity and privateness thus become, at least in part, a matter of choice.

The whole process is discussed in greater detail in Tirassa, Bosco, and Colle (in press). Let us just say here that, if cognition is conceived of as a biological phenomenon, then ontogeny (a notion that is more akin to maturation as it is conceived of, for example, in embryology, rather than to learning or development as they are usually conceived of in psychology) becomes a natural explanatory strategy, despite the neglect in which it fell after the failure of learning-based theories of cognition and the rise of classical, information-processing cognitive science.

\section{Acknowledgements}

This research was funded by the Italian Ministry of Education, University and Research (FIRB Project, research code RBAU01JEYW). We are grateful to the participants to the 4th Conference on Collective Intentionality (CollIntIV, Siena, October 13-15, 2004), as well as to the anonymous reviewers of this paper, for the improvements that their comments and discussions brought to our work.

\section{References}

Airenti, G. (1998). Dialogue in a developmental perspective. In S. Cmejrková, J. Hoffmannová, O. Müllerová, \& J. Svetlá (Eds.), 6th 
Conference of the International Association for Dialogue Analysis (pp. 283-290). Tübingen: Niemeyer.

Airenti, G., Bara, B. G., \& Colombetti, M. (1993). Conversation and behavior games in the pragmatics of dialogue. Cognitive Science, 17, 197-256.

Allen, J. F., \& Perrault, C. R. (1980). Analyzing intention in utterances. Artificial Intelligence, 15, 143-178.

Austin, J. L. (1962). How to do things with words (2nd ed. revised by J. O. Ormson, \& M. Sbisà, 1975). London: Oxford University Press.

Bara, B. G., \& Tirassa, M. (1999). A mentalist framework for linguistic and extralinguistic communication. In S. Bagnara (Ed.), 3rd European conference on cognitive science (pp. 285-290). Roma: IP-CNR.

Barkow, J. H., Cosmides, L., \& Tooby, J. (Eds.) (1992). The adapted mind. Evolutionary psychology and the generation of culture. New York and Oxford: Oxford University Press.

Baron-Cohen, S. (1995). Mindblindness. An essay on autism and theory of mind. Cambridge, MA: MIT Press.

Baron-Cohen, S., Leslie, A. M., \& Frith, U. (1985). Does the autistic child have a theory of mind? Cognition, 21, 37-46.

Bates, E., Camaioni, L., \& Volterra, V. (1979). The acquisition of performatives prior to speech. In E. Ochs \& B. B. Schieffelin (Eds.), Developmental pragmatics (pp. 111-129). New York: Academic.

Bateson, G. (1972). Steps to an ecology of mind. New York: Ballantine.

Bosco, F. M., \& Tirassa, M. (1998). Sharedness as an innate basis for communication in the infant. In M. A. Gernsbacher \& S. J. Derry (Eds.), 20th Annual conference of the Cognitive Science Society (pp. 162-166). Mahwah, NJ: Erlbaum.

Bowlby, J. (1969). Attachment and loss: I - attachment. London: Hogarth.

Bratman, M. E. (1987). Intentions, plans, and practical reason. Cambridge, MA: Harvard University Press.

Bratman, M. E. (1990). What is intention? In P. R. Cohen, J. Morgan, \& M. E. Pollack (Eds.), Intentions in communication (pp. 15-31). Cambridge, MA: MIT Press.

Braten, S. (1992). The virtual other in infants' minds and social feelings. In H. Wold (Ed.), The dialogical alternative (pp. 77-97). Oslo: Scandinavian University Press.

Bruner, J. S. (1977). Early social interaction and language acquisition. In H. R. Schaffer (Ed.), Studies in mother-infant interaction (pp. 271-289). London: Academic Press.

Bruner, J. S. (1982). Formats of language acquisition. American Journal of Semiotics, 1, 1-16.

Bruner, J. S. (1990). Acts of meaning. Cambridge: Cambridge University Press.

Carassa, A., Morganti, F., \& Tirassa, M. (2004). Movement, action, and situation: presence in virtual environments. In M. Alcañiz Raya \& B. Rey Solaz (Eds.), 7th Annual international workshop on presence (pp. 7-12). Valencia, Spain: Editorial Universidad Politécnica de Valencia.

Carassa, A., Morganti, F., \& Tirassa, M. (2005). A situated cognition perspective on presence. In B. G. Bara, L. Barsalou, \& M. Bucciarelli (Eds.), 27th Annual conference of the Cognitive Science Society (pp. 384-389). Mahwah, NJ: Erlbaum.

Carey, S. (1995). On the origin of causal understanding. In A. James Premack, D. Premack, \& D. Sperber (Eds.), Causal cognition (pp. 268-301). Oxford: Clarendon.

Carpenter, M., Nagell, K., \& Tomasello, M. (1998). Social cognition, joint attention, and communicative competence from 9 to 15 months of age. Monographs of the Society for Research in Child Development, 63 (4, Serial No. 255).

Clancey, W. J. (1997a). The conceptual nature of knowledge, situations and activity. In P. J. Feltovich, K. M. Ford, \& R. R. Hoffmann (Eds.), Expertise in context (pp. 247-291). Menlo Park, CA: The AAAI Press.

Clancey, W. J. (1997b). Situated cognition. On human knowledge and computer representations. Cambridge: Cambridge University Press.

Clark, H. H. (1992). Arenas of language use. Chicago, IL: University of Chicago Press.

Clark, H. H. (1996). Using language. Cambridge: Cambridge University Press.
Clark, H. H., \& Marshall, C. R. (1981). Definite reference and mutual knowledge. In A. K. Joshi, B. L. Webber, \& I. A. Sag (Eds.), Elements of discourse understanding (pp. 10-63). Cambridge: Cambridge University Press.

Cohen, P. R., Morgan, J., \& Pollack, M. E. (Eds.). (1990). Intentions in communication. Cambridge, MA: MIT Press.

Cohen, P. R., \& Perrault, C. R. (1979). Elements of a plan-based theory of speech acts. Cognitive Science, 3, 177-212.

Cohn, J. F., \& Tronik, E. Z. (1989). Specificity of infants' response to mothers' affective behavior. Journal of the American Academy of Child an Adoloscent Psychiatry, 28, 242-248.

Cole, M. (1996). Cultural psychology. A once and future discipline. Cambridge, MA: Harvard University Press.

Colombetti, M. (1993). Formal semantics for mutual belief. Artificial Intelligence, 62, 341-353.

Cosmides, L., \& Tooby, J. (1994a). Beyond intuition and instinct blindness: Toward an evolutionarily rigorous cognitive science. Cognition, 50, 41-77.

Cosmides, L., \& Tooby, J. (1994b). Origins of domain specificity: The evolution of functional organization. In L. A. Hirschfeld \& S. A. Gelman (Eds.), Mapping the mind. Domain specificity in cognition and culture (pp. 85-116). Cambridge: Cambridge University Press.

Dennett, D. C. (1978). Beliefs about beliefs. Behavioral and Brain Sciences, $1,568-570$.

Dennett, D. C. (1987). The intentional stance. Cambridge, MA: MIT Press.

Edelman, G. M. (1992). Bright air, brilliant fire: on the matter of the mind. New York: Basic Books.

Fodor, J. A. (1983). The modularity of mind. An essay on faculty psychology. Cambridge, MA: MIT Press.

Fodor, J. A. (2000). The mind doesn't work that way. Cambridge, MA: MIT Press.

Fogel, A. (1993). Two principles of communication: co-regulation and framing. In J. Nadel \& L. Camaioni (Eds.), New perspectives in early communicative development (pp. 9-22). London: Routledge.

Frith, C. D. (1992) The cognitive neuropsychology of schizophrenia. Hove, UK, and Hillsdale, NJ: Erlbaum.

Gallese, V., \& Goldman, A. (1998). Mirror neurons and the simulation theory of mindreading. Trends in Cognitive Science, 2, $493-501$.

Gallese, V., Keysers, C., \& Rizzolatti, G. (2004). A unifying view of the basis of social cognition. Trends in Cognitive Sciences, 8 , 396-403.

Garfield, J. L., Peterson, C. C., \& Perry, T. (2001). Social cognition, language acquisition and the development of the theory of mind. Mind and Language, 16, 494-541.

Gergely, G., \& Watson, J. (1996). The social biofeedback model of parental affect-mirroring. International Journal of Psycho-Analysis, 77, 1181-1212.

Gergely, G., \& Watson, J. (1999). Early social-emotional development: contingency perception and the social biofeedback model. In P. Rochat (Ed.), Early social cognition: understanding others in the first months of life (pp. 101-137). Hillsdale, NJ: Lawrence Erlbaum.

Goldman, A. (1993). The psychology of folk psychology. Behavioral and Brain Sciences, 16, 15-28.

Gopnik, A. (1993). How we know our minds. Behavioral and Brain Sciences, 16, 1-14.

Gordon, R. M. (1986). Folk psychology as simulation. Mind and Language, 1, 158-171.

Gordon, R. M. (1996). Radical simulationism. In P. Carruthers \& P. K. Smith (Eds.), Theories of theories of mind (pp. 11-21). Cambridge: Cambridge University Press.

Grice, H. P. (1957). Meaning. The Philosophical Review, 67, 377-388.

Grice, H. P. (1982). Meaning revisited. In N. V. Smith (Ed.), Mutual knowledge (pp. 222-243). New York: Academic Press.

Grice, H. P. (1989). Studies in the way of words. Cambridge, MA: Harvard University Press.

Guidano, V. F. (1987). Complexity of the self: a developmental approach to psychopathology and therapy. New York: Guilford. 
Guidano, V. F. (1991). The self in process. Toward a post-rationalist cognitive therapy. New York: Guilford.

Harris, P. L. (1991). The work of the imagination. In A. Whiten (Ed.), Natural theories of mind (pp. 283-304). Oxford: Blackwell.

Hobson, R. P. (1993). Autism and the development of mind. Hove, UK: Erlbaum.

Jacob, P., \& Jeannerod, M. (2005). The motor theory of social cognition: a critique. Trends in Cognitive Sciences, 9, 21-25.

Johnson, M. (1987). The body in the mind: the bodily basis of imagination, reason and meaning. Chicago, IL: University of Chicago Press.

Leslie, A. M. (1994a). Pretending and believing: issues in the theory of ToMM. Cognition, 50, 211-238.

Leslie, A. M. (1994b). ToMM, ToBy, and agency: core architecture and domain specificity. In L. A. Hirschfeld \& S. A. Gelman (Eds.), Mapping the mind. Domain specificity in cognition and culture (pp. 119-148). Cambridge: Cambridge University Press.

Lewontin, R. (2000). The triple helix: gene, organism and environment. Cambridge, MA: Harvard University Press.

Meltzoff, A. N., \& Gopnik, A. (1993). The role of imitation in understanding persons and developing theories of mind. In S. BaronCohen, H. Tager-Flusberg, \& D. Cohen (Eds.), Understanding other minds (pp. 335-366). Oxford: Oxford University Press.

Meltzoff, A. N., \& Moore, M. K. (1983). Newborn infants imitate adult facial gestures. Child Development, 54, 702-709.

Meltzoff, A. N., \& Moore, M. K. (1989). Imitation in newborn infants: exploring the range of gestures imitated and the underlying mechanisms. Developmental Psychology, 25, 954-962.

Meltzoff, A. N., \& Moore, M. K. (1997). Explaining facial imitation: theoretical model. Early Development and Parenting, 6, 179-192.

Minsky, M. (1985). The society of mind. New York: Simon and Schuster.

Morton, J., \& Johnson, M. H. (1991). CONSPECT and CONLEARN: a two process theory of infant face recognition. Psychological Review, 98, 164-181.

Murray, L., \& Trevarthen, C. (1985). Emotional regulation of interaction between two-month-olds and their mothers. In T. M. Field \& N. A Fox (Eds.), Social perception in infant (pp. 177-197). Norwood, NJ: Ablex.

Nagel, T. (1986). The view from nowhere. Oxford: Oxford University Press.

Papousek, H., \& Papousek, M. (1974). Mirror-image and self recognition in young infants: a new method of experimental analysis. Developmental Psychobiology, 7, 149-157.

Premack, D. (1988). 'Does the chimpanzee have a theory of mind?' revisited. In R. W. Byrne \& A. Whiten (Eds.), Machiavellian intelligence: social expertise and the evolution of intellect in monkeys, apes, and humans (pp. 161-179). Oxford: Clarendon Press.

Premack, D. (1990). The infant's theory of self-propelled objects. Cognition, 36, 1-16.

Rao, A., \& Georgeff, M. (1992). An abstract architecture for rational agents. In B. Nebel, C. Rich, \& W. Swartout (Eds.), 3rd International conference on knowledge representation and reasoning (pp. 439-449). San Mateo, CA: Morgan Kaufmann.

Reddy, V., Hay, D., Murray, L., \& Trevarthen, C. (1997). Communication in infancy: mutual regulation of affect and attention. In G. Bremner, A. Slater, \& G. Butterworth (Eds.), Infant development: recent advances (pp. 247-273). Hove: Psychology Press.

Risjord, M. (1996). Meaning, belief, and language acquisition. Philosophical Psychology, 9, 465-475.

Rizzolatti, G., Fadiga, L., Gallese, V., \& Fogassi, L. (1996). Premotor cortex and the recognition of motor actions. Cognitive Brain Research, $3,131-141$.

Rochat, P., \& Morgan, R. (1995). Spatial determinants in the perception of self-produced leg movements in 3- to 5-month-old infants. Developmental Psychology, 31, 626-636.

Schiffer, S. R. (1972). Meaning. Oxford: Oxford University Press.

Searle, J. R. (1969). Speech acts: an essay in the philosophy of language. London: Cambridge University Press.
Searle, J. R. (1979). Expression and meaning. Cambridge: Cambridge University Press

Searle, J. R. (1980). Minds, brains, and programs. Behavioral and Brain Sciences, 3, 417-456.

Searle, J. R. (1983). Intentionality: an essay in the philosophy of mind. Cambridge: Cambridge University Press.

Searle, J. R. (1992). The rediscovery of the mind. Cambridge, MA: MIT Press.

Sperber, D., \& Wilson, D. (1986). Relevance. Communication and cognition. Oxford: Blackwell.

Stern, D. N. (1985). The interpersonal world of the infant. New York: Basic Books.

Stern, D. N. (1995). Self/other differentiation in the domain of intimate socio-affective interaction: some considerations. In P. Rochat (Ed.), The self in infancy: theory and research (pp. 419-429). Amsterdam: Elsevier.

Strawson, P. F. (1964). Intention and convention in speech acts. The Philosophical Review, 73, 439-460.

Thompson, R. (1998). Empathy and its origins in early development. In S. Braten (Ed.), Intersubjective communication and emotion in early ontogeny (pp. 144-157). Paris: Cambridge University Press.

Tirassa, M. (1997). Mental states in communication. 2nd European conference on cognitive science. Manchester, UK, 103-114.

Tirassa, M. (1999a). Communicative competence and the architecture of the mind/brain. Brain and Language, 6, 419-441.

Tirassa, M. (1999b). Taking the trivial doctrine seriously: functionalism, eliminativism, and materialism. Behavioral and Brain Sciences, 22, $851-852$.

Tirassa, M. (in press). Agencies. In L. A. Pérez Miranda, \& J. M. Larrazabal (Eds.), Advances in cognitive science. Dordrecht: Kluwer.

Tirassa, M., Bosco, F. M., \& Colle, L. (in press). Rethinking the ontogeny of mindreading. Consciousness and Cognition.

Tirassa, M., Carassa, A., \& Geminiani, G. (2000). A theoretical framework for the study of spatial cognition. In S. O Nualláin (Ed.), Spatial cognition. Foundations and applications (pp. 19-31). Amsterdam and Philadelphia: Benjamins.

Tomasello, M. (1995). Joint attention as social cognition. In C. Moore \& P. Dunham (Eds.), Joint attention: its origins and role in development (pp. 103-130). Hillsdale, NJ: Erlbaum.

Tomasello, M., \& Haberl, K. (2003). Understanding attention: 12- and 18month-olds know what is new for other persons. Developmental Psychology, 39, 906-912.

Trevarthen, C. (1977). Descriptive analyses of infant communicative behavior. In H. Schaffer (Ed.), Determinants of infant behavior (pp. 227-270). London: Academic.

Trevarthen, C. (1979). Communication and cooperation in early infancy: a description of primary intersubjectivity. In M. Bullowa (Ed.), Before speech. The beginning of interpersonal communication (pp. 321-347). Cambridge: Cambridge University Press.

Trevarthen, C. (1993a). The function of emotions in early infant communication and development. In J. Nadel \& L. Camaioni (Eds.), New perspectives in early communicative development (pp. 48-81). London: Routledge.

Trevarthen, C. (1993b). The self born in intersubjectivity: the psychology of an infant communicating. In U. Neisser (Ed.), The perceived self: ecological and interpersonal sources of self-knowledge (pp. 121-173). New York: Cambridge University Press.

Varela, F. (1996). A science of consciousness as if experience mattered. In S. R. Hameroff, A. W. Kaszniak, \& A. C. Scott (Eds.), Toward a science of consciousness (pp. 31-44). Cambridge, MA: MIT Press.

Varela, F. J., Thompson, E., \& Rosch, E. (1991). The embodied mind. Cognitive science and human experience. Cambridge, MA: MIT Press.

Vygotsky, L. S. (1978). Mind in society. Cambridge: Harvard University Press.

Vygotsky, L. S. (1981). The genesis of higher mental functions. In J. V. Wertsch (Ed.), The concept of activity in Soviet psychology (pp. 144-188). Armonk, NY: M.E. Sharpe. 